\title{
TIME REDUCTION EFFECTS OF STEEL CONNECTED PRECAST CONCRETE COMPONENTS FOR HEAVILY LOADED LONG-SPAN BUILDINGS
}

\author{
Ho-Haeng LEE (1) 1, Ki-Ho KIM (1) , Seunghyun SON(1) \\ Kwangheon PARK (D)2 ${ }^{2}$, Sunkuk KIM (1D) ${ }^{*}$ \\ ${ }^{1}$ Department of Architectural Engineering, Kyung Hee University, Suwon, Republic of Korea \\ ${ }^{2}$ Department of Nuclear Engineering, Kyung Hee University, Suwon, Republic of Korea
}

Received 15 June 2019; accepted 12 August 2019

\begin{abstract}
The characteristics of large logistics buildings are their long spans and the ability to take heavy loads. Usually, PC components are used for their frames to ensure quick construction. However, the erection of most pin jointed PC structures increases the time and the cost incurred for ensuring structural stability and construction safety. To solve this problem, "smart" frames have been developed, which have tapered steel joints at both ends of the PC components. A smart frame with the moment frame concept not only assures structural stability and construction safety, but it also simplifies and quickens the erection because of its tapered joint detail. The purpose of this study is to compare the erection time and cost effects of the steel connected PC components for heavily loaded long-span logistics buildings with the existing PC frames. For this study, we selected a logistics building constructed with PC components and redesigned it as the smart frame, and the erection simulations were performed. We analyzed the time reduction effects of the smart frame. Our results confirmed that the use of the smart frame reduced the erection time and cost practically. Our investigations will help develop the erection simulation algorithms for smart frames.
\end{abstract}

Keywords: PC erection, logistics building, time reduction, cost reduction, steel connected PC frame.

\section{Introduction}

A rapid increase in the online sales of large retailers has increased the demand for large logistics buildings worldwide. The characteristics of these buildings are their long spans, large floor heights, and ability to take heavy loads. Mostly, precast concrete (PC) components are adopted for businesses that need to open quickly (Rajagopal, 2010; S. H. Kim, Choi, S. K. Kim, \& Lee, 2010). Most PC frames having heavily loaded long-span logistics buildings are designed with pin joints, which are installed by using a simple mounting (Elliott \& Jolly, 2013). Consequently, structural stability and construction safety problems might occur during PC member erection (Fathi, Parvizi, Karimi, \& Afreidoun, 2018). Solving this problem would increase the construction time and costs (Hong, G. Kim, Lim, \& S. Kim, 2017). In other words, a large amount of equipment and human resources are necessary to safely connect the girder with the column, which makes time a critical factor. This problem can be easily solved by using "smart" frames installed with tapered steel joints similar to a steel structure at both ends of the precast concrete components (Lee, S. E. Kim, G. H. Kim, Joo, \& S. K. Kim, 2011). Similar to steel structures, smart frames that involve the moment frame action not only secure the structural stability and the construction safety during the erection process (which is the problem of pin-joint PC frames), but their tapered joint detail also makes the erection easier and quicker than regular frame constructions (Son, Lim, \& Kim, 2018; Kim et al., 2010). In particular, multiple studies have proven that smart frames are superior to existing PC frames in terms of their structural stability, construction safety, and economic feasibility (Joo, S. E. Kim, G. J. Lee, S. K. Kim, \& S. H. Lee, 2012a; Lim, Lee, \& Kim, 2015; S. Kim, Hong, J. H. Kim, \& J. T. Kim, 2013a). When smart frames with the above-mentioned advantages are adopted (instead of PC frames) for heavily loaded long-span logistics buildings, cost reduction and shortened construction time is expected to be realized.

${ }^{*}$ Corresponding author. E-mail: kimskuk@khu.ac.kr 
The purpose of this study is to compare the erection time and cost effects of the steel connected PC components (i.e., the smart frames) for heavily loaded longspan logistics buildings with the existing PC frames. We used the case study of a logistics building constructed with pin-joint PC components. Then, the same building was redesigned using a smart frame, and the installation simulations were performed by considering the site conditions. Then, we compared the results. We first considered the erection method of heavily loaded long-span logistics buildings. Second, we examined the characteristics of the smart frame and the erection process in comparison with the pin-joint PC frame method. Third, we chose a logistics building constructed with the pin-joint PC frame method as the case study, and the erection simulations were implemented by adopting the smart frame. Then, we compared the erection time of the smart frames with the erection time when the pin-joint PC frames were used. Fourth, we analyze the cost reduction associated with the time reduction and discuss the study results.

\section{Preliminary study}

\subsection{PC erection of heavily loaded long-span buildings}

We used PC erection for heavily loaded long-span buildings to shorten the construction time without being seriously impacted by the climate and weather changes (Lee, Lim, \& Kim, 2016). Time reduction was found to be effective for quick business openings and for a reduced payback period (Son et al., 2018). In addition, it is difficult and dangerous to perform temporary work, such as formworks, because the floor of the logistics buildings is very high. Thus, it is advantageous to adopt PC erections that may minimize the amount of formwork (Kim et al., 2010). In general, there are three types of PC component erections (see Figure 1).

As illustrated in Figure 1(a), a floor-by-floor erection secures the structural stability of buildings because the joint concrete is poured after installing the columns, gird-

a) Floor by floor erection

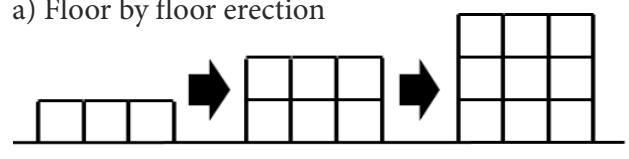

b) Cascading erection

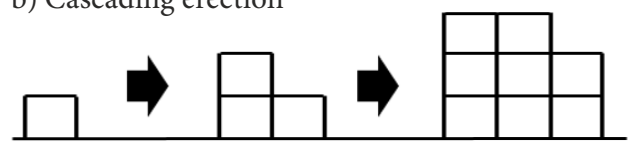

c) Section by section erection

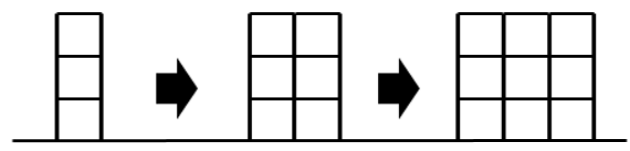

Figure 1. Erection methods of PC components (Kim et al., 2013a) ers, and slabs required for each floor. Then, the upper floor members are repeatedly mounted, which makes the activities sequence critical (Son et al., 2018). Most pin-joint PC frames are erected in this way. Figure 1(b) shows a cascading erection in which the members are piled in cascades within the coverage of a crane boom. This method is applied when there is not enough time for floor-by-floor erection. Although cascading erection is effective in reducing the time, it is difficult to erect all the PC components using the cascading method because the coverage of the crane boom is limited. Figure 1(c) demonstrates a section-by-section erection. Unlike other erection methods, the PC components of a specific section are erected on all floors, which make it easier to ensure the efficiency of the equipment operation and the work space (Lim, Joo, Lee, \& Kim, 2011). Furthermore, the components can be erected in all directions when a crane is accessible (Kim et al., 2010). In the case of pin-joint PC frames, mostly floor-by-floor erection is adopted; cascading erection is adopted for reducing the construction time (Nawy, 2008). However, when moment frames, such as smart frames, are erected, any of the three erection methods may be applied.

\subsection{Smart frame}

During the erection of pin-joint PC frames, structural stability and construction safety should be secured; therefore, there are limits to the erection method and a substantial amount of time is required for the erection (Polat, 2008). Moreover, it is difficult to calibrate the errors that may occur when pouring joint concrete after placing the girders on the top of columns (Arditi, Ergin, \& Günhan, 2000). As shown in Figure 2, smart frames with tapered steel connections of columns and girders not only secure a rapid and precise erection, but they also provide structural stability as soon as the connection is made (Hong, Park, Kim, \& Nzabonimpa, 2016; Kim, Hong, \& Lim, 2017).

As illustrated in Figure 2(a), we used bolts to connect the composite precast concrete (CPC) components of the columns and girders similar to steel structure (Hong et al., 2017). As shown in Figure 2(b), the steel can be arranged only on the joints of columns and girders for general buildings within a span of approximately $8 \mathrm{~m}$. Therefore, this structure has the advantages of both reinforced concrete (RC) and steel frame structures (Nawy, 2008). All the joints are connected with bolts; therefore, the structural performance of smart frames is similar to that of steel structures. Also, we poured the concrete into the joints after erection, which made it a moment frame (Polat, 2008; Arditi et al., 2000).

Table 1 shows a comparison between the conventional $\mathrm{PC}$ frames and the smart frames that use steel-jointed CPC components. The conventional PC frames are structurally pin jointed, whereas the smart frames are momentjointed similar to the steel frames (Kim et al., 2017; Lee, Park, Lim, \& Kim, 2013).

We erected a conventional PC frame by using the floor-by-floor method, as shown in Figure 1(a), mainly for structural stability and construction safety. We also 
a) SMART frame for long span and heavy loaded logistics buildings

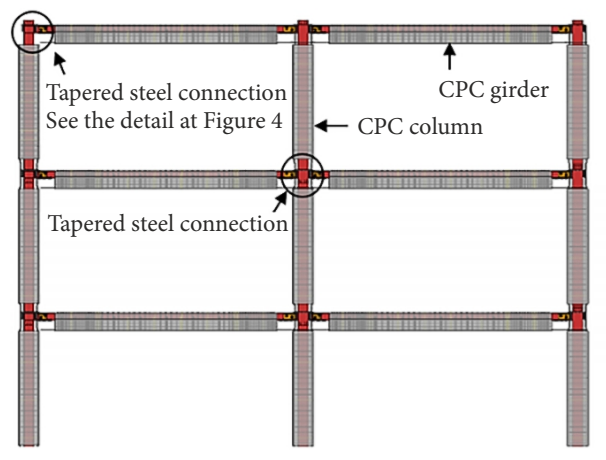

b) SMART frame for buildings with less than $8 \mathrm{~m}$ span
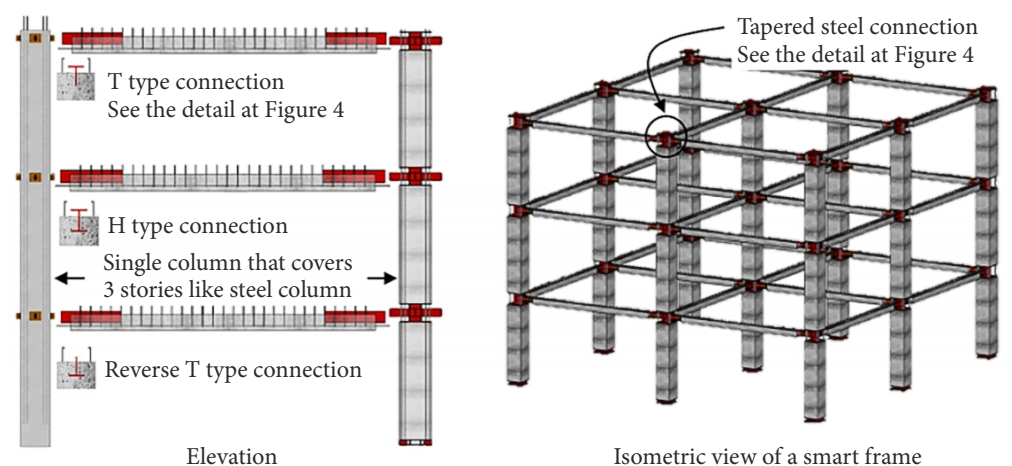

Isometric view of a smart frame

Figure 2. Configurations of a smart frame (Lee, Hong, Lim, \& Kim, 2015)

Table 1. Comparison of the conventional PC and smart frames (Kim et al., 2010; Son et al., 2018)

\begin{tabular}{|c|c|c|}
\hline Description & Conventional PC frame & Smart frame \\
\hline Main component & Precast concrete $(\mathrm{PC})$ components & Composite precast concrete (CPC) components \\
\hline Structural joint & Pin joint & Moment joint \\
\hline Erection method & $\begin{array}{l}\text { Mainly floor-by-floor and optionally cascading } \\
\text { erection }\end{array}$ & $\begin{array}{l}\text { All erections including floor-by-floor, cascading } \\
\text { and section-by-section are possible }\end{array}$ \\
\hline Resistance to lateral force & Heavy RC shear walls and/or cores, braces & Structural frame itself \\
\hline Role of cores & Shear wall resisting to lateral force & Simple vertical passageway \\
\hline Critical path & Mainly RC core wall & CPC erection \\
\hline Slab system & Use expensive PC slabs, such as Double-T and RPS & Use relatively cheap deck plates such as deep deck \\
\hline Planning of crane paths & Limited due to floor-by-floor erection & Possible planning like steel erection \\
\hline Safety and stability & Lateral support required during erection & No lateral support required during erection \\
\hline
\end{tabular}

partially erected a frame by using the cascading method, as shown in Figure 1(b), for shortening the construction time. Therefore, there were many constraints in the planning for the crane path (Arditi et al., 2000). However, a smart frame is available in all three erections (see Figure 1); therefore, crane path planning can be easily and diversely established (Joo et al., 2012).

Resistance to the lateral force of the PC frame is made up of heavy RC shear walls and/or cores and braces, whereas the smart frame itself makes resistance to the lateral force similar to that of steel frames (Holden, Restrepo, \& Mander, 2003). Therefore, in the case of PC frames, the building cores generally act as the shear walls resisting the lateral forces, whereas these cores act only as vertical passageways in smart frames (Lee et al., 2015). Consequently, the RC cores of the PC frame are very thick and designed for heavy reinforcement, and in most cases, they are scheduled as critical activities during construction (H. K. Choi, Y. C. Choi, \& C. S. Choi, 2013). However, the cores of the smart frame are simple structures that support their own weight; therefore, they are constructed independently and quickly during the CPC erection (K. H. Kim, T. O. Lee, S. H. Lee, \& S. K. Kim, 2012). The PC frame requires heavy and expensive PC slabs, such as Double-T, plastic ribbed slabs, and so on (Casadei, Nanni, Alkhrdaji, \& Thomas, 2005; Yardim, Waleed, Jaafar, \& Laseima, 2013). Howev- er, relatively light and cheap deck plates can be used for the smart frames (Kim et al., 2012). Finally, during the erection process, the $\mathrm{PC}$ frame requires temporary lateral support for construction safety and structural safety, but the smart frame only needs props to maintain verticality (Hurst, 2017; Hong et al., 2008).

\subsection{Advantages of a smart frame}

A smart frame has three main advantages: (i) expanded available space, (ii) construction time reduction, and (iii) increased convenience in erection (Lee et al., 2011; Kim et al., 2010; Lim et al., 2011). First, the sectional sizes of the CPC components in the smart frames are relatively smaller than the sizes of the PC components for the same design conditions; this results in an increase in the available space (Lim et al., 2011). As shown in Figure 2(a), when a steel frame is buried in the entire span, the sectional sizes of the columns and beams will be approximately $20 \%$ less than the sectional sizes of the columns and beams in the existing PC structure (Hong et al., 2009). The available space will be larger than the existing PC structure whereas the structural performance would remain the same. In addition, the amount of concrete and forms decrease as the sectional size is reduced, but the quantity of the steel frames increases. As a result, the material and production 
cost of the CPC components was approximately $2 \%$ to $3 \%$ lower as compared with that of the PC components (Hong et al., 2010a; Hong, G. Lee, S. Lee, \& Kim, 2014). Second, for heavily loaded long-span buildings, there were fewer critical activities when smart frames were adopted instead of the existing pin-jointed PC frames (see Figure 3 ); this significantly reduced the construction time (Lee et al., 2016). As shown in Figure 3(a), all the processes were critical ranging from the column erection to the completion of the curing after casting the topping concrete because of structural stability. However, the smart frame can secure structural stability when completing steps 1 to 3 shown in Figure 3(b). In Figure 3(b), "Step 3. Installing PC slabs or deck plates" is listed as a critical activity for construction safety rather than structural stability. Step 3 may be skipped for further time reduction but any risk arising because of the lack of working space should not be permitted. For reference, the activities omitted from Figure 3(b) when compared with those in Figure 3(a) are not critical activities, and they can be performed during the upper CPC erection.

a) Pin-jointed PC frame

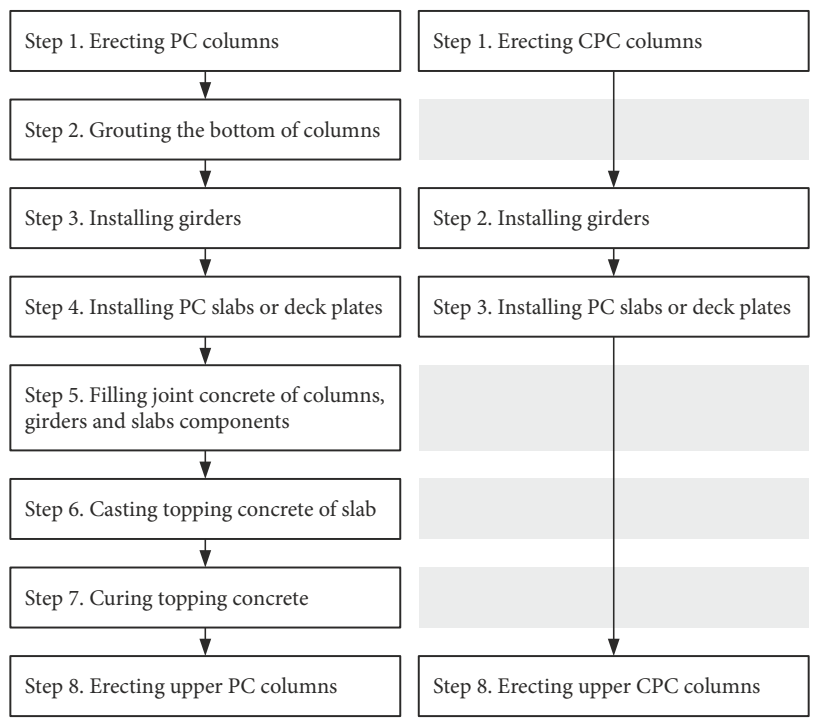

Figure 3. Critical activity analysis of PC and smart frames

a) Sliding

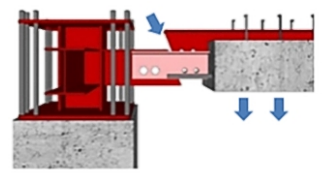

Side view

c) Bolting

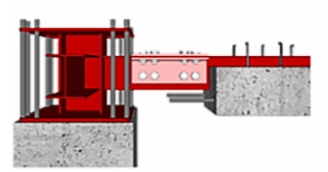

Side view

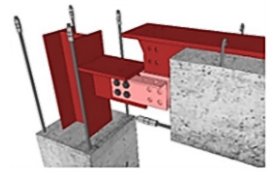

Bird's eye view

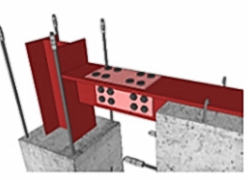

Bird's eye view
As shown in Figure 3(a), plumbing with propping for the PC columns of the PC frame needs to be done first, and then bottom grouting should be performed for structural stability. The upper girders need to be installed first, and the PC slabs or the deck plates are to be installed subsequently. Then, the joint concrete is poured to bind the column and girder components to ensure structural stability. After installing the remaining slab rebar, the topping concrete is poured, and curing is executed. All these are critical activities. For reference, steps 6 and 7 may be omitted, and step 8 may be performed for reducing the construction time. However, to perform step 8, the lower part of the upper PC columns should be filled with the padding concrete; the filling needs to be as thick as the slab. Third, the smart frame not only secures a quicker and more precise erection than the steel frame structure owing to the tapered connection with the L-shaped steel guide (see Figure 4), but it also ensures improved structural stability and construction safety as compared with the existing PC frame. The study conducted by Hong et al. (2017) details the engineering principles and the effects related to the tapered connection with the L-shaped steel guide. As shown in Figure 4, the steel web section located at both ends of a girder was inserted into the L-shaped plates pre-installed in the T-type bracket of a column, as shown in Figure 4(a). When the crane shackle is quickly and safely set because of the girder's gravity load (see Figure 4(b)), it is immediately removed for the next erection. The crane lifts another girder while bolting is performed, as shown in Figure 4(c).

As illustrated in Figure 4(d), the L-shaped reinforcement plates with tapered webs of girder steels have three roles (Hong et al., 2017). First, the flange reinforcement performs a temporary safe receipt of the girder's web steel in the reinforcement plates when an axial eccentricity of the beam occurs while approaching the girder. Furthermore, these plates support the weight of the girder after the girder reaches the setting location. Second, the web reinforcement acts as a guide to axially align the column and the beam steel, which leads it to the exact setting location along the web section. Third, the rounded corner of the reinforcement plates slide and set the girder steel inside the

b) Setting

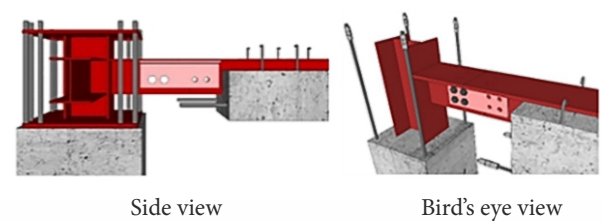

d) L-shaped plates

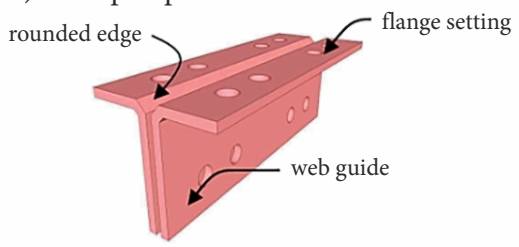

Figure 4. Connection process of a smart frame 
reinforcement plate along the slope because of the gravitational load of the beam. As a result, smart frames applied with the tapered connection of the L-shaped plate reduce the erection time and increase precision when compared with the steel frames and the existing PC frames. Furthermore, the structural stability and construction safety of the smart frames during erection are superior to those of the existing PC frames (Lee et al., 2011; Joo et al., 2012a; Hong et al., 2010b). Finally, a section-by-section erection was applied for the smart frames, as shown in Figure 1 (c). In this case, the PC components could be erected within a smaller working radius close to the structure; therefore, a crane with less lifting capacity may be used as compared with the pin-joint PC erection. A small lifting capacity means better mobility, which results in quicker erection (Hong et al., 2009). The rental cost will be reduced as well. The crane capacity was determined by the lifting load and the working radius. When the smart frame was applied, it was possible to have erection with a reduced lifting load and working radius; this makes it more advantageous than pin-joint PC erection in terms of the time and cost.

However, CPC components should be made more precisely than convention PCs. This is because the accuracy of the erection cannot be secured if the connection steel is slightly misplaced during the CPC manufacturing process. And the erection of CPC components should follow the precision and process of steel erection.

\section{Erection time analysis of a PC frame}

\subsection{Brief description of the case project}

Table 2 gives a brief description of the case project selected for analyzing the effects of a smart frame application. The case project is a logistics building erected with pin-joint PC components, and it is characterized by a high floor and a heavy unit member. The PC components consisted of 942 columns, 1273 girders, and 3985 slabs. The length and weight of the general column were $9.2 \mathrm{~m}$ and 14.13 tons, respectively. The length and weight of the girder components were $11 \mathrm{~m}$ and 26.40 tons, respectively. The longest girder component was 23-m long and weighed 85.39 tons. The columns and girders were structured in the PC frames

a) Site condition

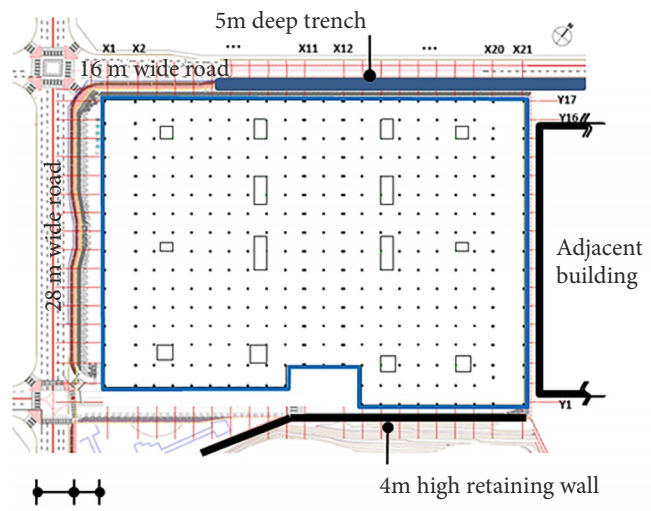

Table 2. Brief description of the project

\begin{tabular}{|l|l|}
\hline \multicolumn{1}{|c|}{ Item } & \multicolumn{1}{c|}{ Contents } \\
\hline Site Location & Cheonan-si, Korea Republic \\
\hline Usage & Logistics building \\
\hline Total floor area & $167,612 \mathrm{~m}^{2}$ \\
\hline No. of floors & 4 stories (10-m floor height) \\
\hline Structures & $\begin{array}{l}\text { Columns, Girders: PC } \\
\text { Slabs: PC with topping concrete } \\
\text { Cores: Reinforced concrete structure } \\
\text { Roof: Steel structure }\end{array}$ \\
\hline $\begin{array}{l}\text { Number of PC } \\
\text { components }\end{array}$ & $\begin{array}{l}\text { Columns: } 942 \text { units } \\
\text { Girders: } 1273 \text { units } \\
\text { Slabs: 3985 units }\end{array}$ \\
\hline Remarks & $\begin{array}{l}\text { Girder span: } 12 \mathrm{~m} \text { (PC length: } 11 \mathrm{~m}), \\
\text { Longest span: } 24 \mathrm{~m} \text { (PC length: } 23 \mathrm{~m}), \\
\text { Load condition: } 2.4 \text { ton } / \mathrm{m}^{2}\end{array}$ \\
\hline
\end{tabular}

and the slabs in the PC with topping concrete. We designed 14 cores in the RC structure for resistance to the lateral force. The top floor including the roof was designed in a steel structure.

The site condition of this case is shown in Figure 5(a). The logistics building was arranged with minimum free spaces on the site because its land was expensive. An adjacent building was located on the right side of the case site, and a $28-\mathrm{m}$-wide road was on its left side. The upper part of the site bordered a 16-m-wide road with a trench that was 5-m deep, and its lower part was close to a retaining wall that was 4 -m high. Therefore, there was very limited space for the crane to move (see Figure 5(b)). As shown in Figure 6, we assumed five scenarios to establish several erection plans with the crane-moving path. In the final erection plan (see Figure 5(b)), we used three cranes (weighing 550 tons) for the erection of heavy and long PC components by considering the working radius.

It is possible to set up alternative PC erection plans by considering the site conditions, as shown in Figure 6. The alternatives illustrated in Figure 6 are evaluated by influencing factors, such as the time, cost, and crane path (see Table 3 ). As described in Table 3, Plan 1, Plan 3, and Plan 4 have the problems of the erection time being more than the time scheduled or budgeted because of the use of four cranes.

b) PC erection plan

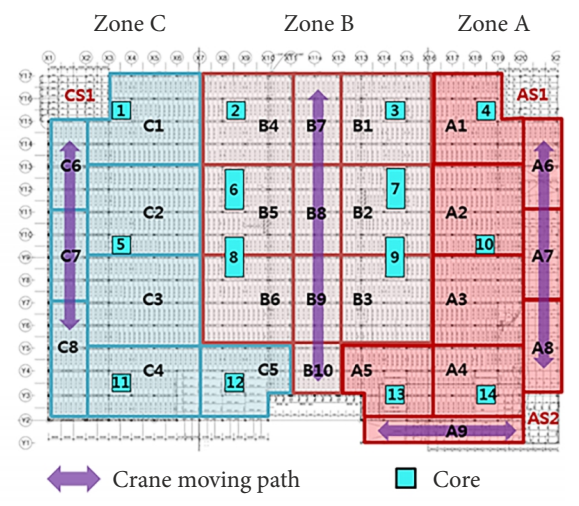

Figure 5. Site conditions and PC erection plan 
a) Plan 1

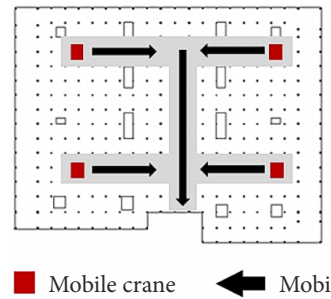

b) Plan 2

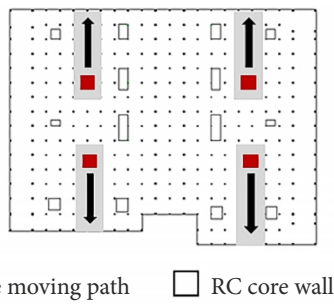

c) Plan 3

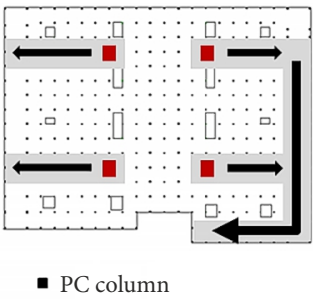

d) Plan 4

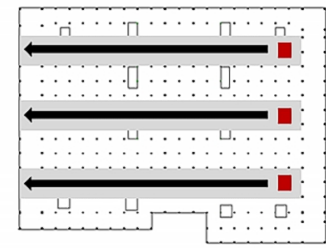

e) Plan 5

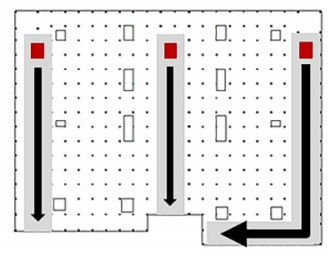

Figure 6. Alternatives of the PC erection plans

Table 3. Evaluation of alternatives

\begin{tabular}{|c|l|l|c|l|}
\hline Alternatives & \multicolumn{1}{|c|}{ Time } & \multicolumn{1}{c|}{ Crane path } & No. of cranes & \multicolumn{1}{c|}{ Evaluation } \\
\hline Plan 1 & Over schedule & Possible & 4 & Over schedule and budget \\
\hline Plan 2 & On schedule & Impossible & 4 & Impossible \\
\hline Plan 3 & On schedule & Possible & 4 & Over budget \\
\hline Plan 4 & Over schedule & Possible & 3 & Over schedule \\
\hline Plan 5 & On schedule & Possible & 3 & On schedule and within budget \\
\hline
\end{tabular}

a) 2 zone erection

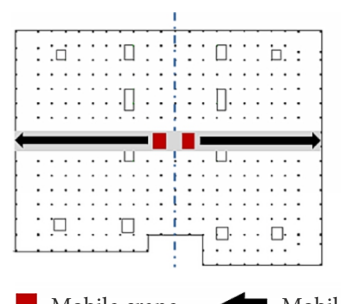

b) 3 zone erection

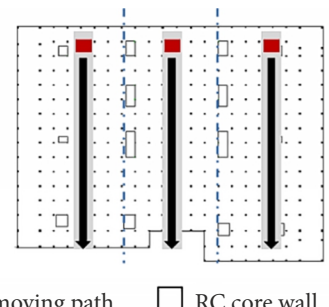

c) 4 zone erection

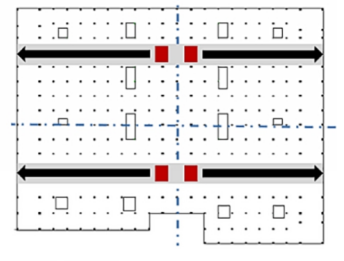

- PC column

Figure 7. Scenarios for site conditions with free crane operation

As illustrated in Figure 5(a), no crane path was available because of the site conditions when Plan 2 was adopted. As a result, Plan 5 was chosen as the final plan that satisfies both the schedule and the budget, and it was divided into the three Zones A, B, and C, as shown in Figure 5(b). Then, each zone was sub-divided into A1-A9, B1-B10, and $\mathrm{C} 1-\mathrm{C} 8$ according to the erection schedule.

In site conditions where cranes are free to operate, three erection scenarios are generally possible, as shown in the Figure A above. In the case of Figure 7(a), the building is divided into 2 zones for erection. The two cranes are used to install the left and right sides simultaneously. In addition, it is possible to install up and down simultaneously. In the case of Figure 7(b), the building is divided into three zones and erection is performed simultaneously at one end of the building using three cranes. In terms of management, it is also possible to install CPCs from the bottom up or from one side to the other. Thus, four alternative scenarios are possible. In the case of Figure 7(c), the building is divided into 4 zones for erection. The four cranes are used to install the left and right sides at the same time. This method can be also installed up and down. As a result, Figure 7 is largely divided into three categories, but 8 alternative scenarios are possible depending on the management strategy.

\subsection{Actual erection of the case building}

We performed the actual erection of the case building based on the plan shown in Figure 5(b), and Figure 8 presents the monthly process. As shown in Figure 1(a), floor-by-floor erection was the first priority. However, cascade erection was applied for partial spans, as shown in Figure 1(b), to meet the tight schedule. A total of 172 calendar days were required to install all the PC components. Figure 8(a) shows the work status one month after the PC erection; three cranes erected some PC columns on the first floor and some girders and slabs on the second floor of the Zones A, B, and C (see Figure 5(b)). The work status after two months is shown in Figure 8(b). Some RC cores on the first floor, PC columns on the first floor, and PC girders and slabs on the second floor were continuously erected. Meanwhile, some PC columns on the second floor, and some PC girders and slabs on the third floor were also erected. Figures $8(\mathrm{c})$ and $8(\mathrm{~d})$ show the work status three and four months later, respectively. The RC cores and the PC erection of the columns, girders, and slabs were performed on all floors simultaneously. Figures $8(\mathrm{e})$ and $8(\mathrm{f})$ show the work statuses after five and six months, respectively; in these figures, the PC erection and RC core installation have been completed on all floors. At the same time, several spans where PC erection 
a) $\mathrm{M}+1$

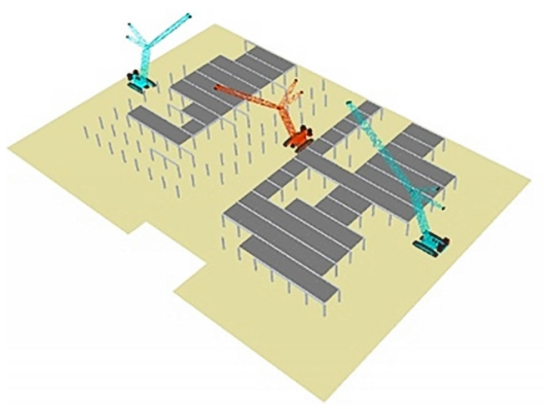

d) $M+4$

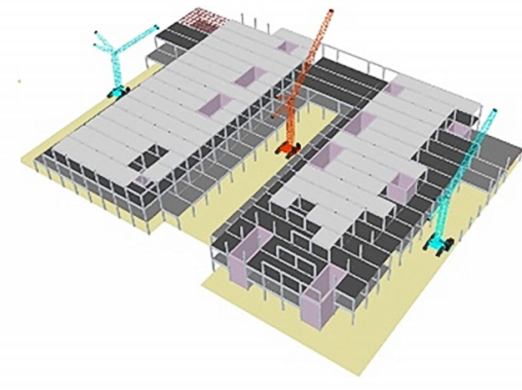

2nd floor slab b) $M+2$

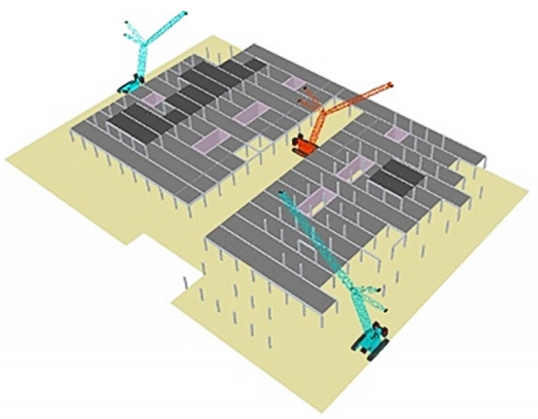

e) $M+5$

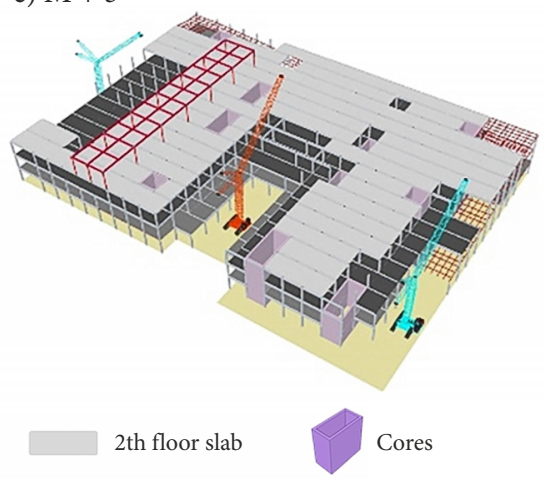

c) $\mathrm{M}+3$

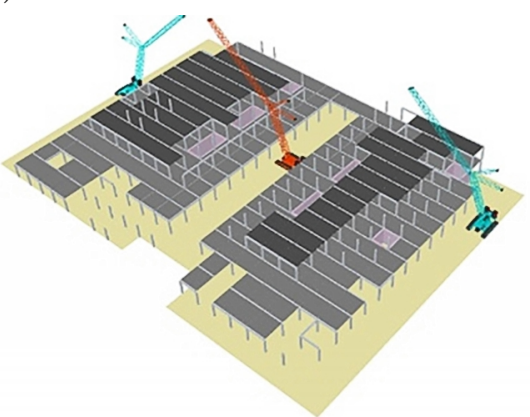

f) $M+6$

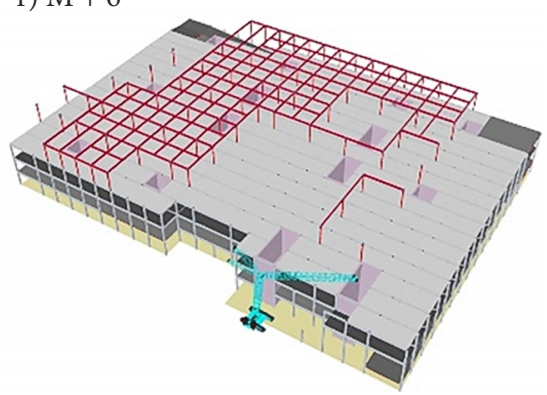

Figure 8. Actual erection status of the case project

has been completed are installed with steel frames on the fourth floor.

In this study, we aim to analyze the reduction in erection time when a steel-joint smart frame is adopted instead of a pin-joint PC component, which requires 172 calendar days for erection. To do this, we changed the design from the application of the conventional PC frame to the smart frame.

\subsection{Problem analysis of the PC erection schedule}

The case site is characterized by the conventional PC frame (unlike the data in Table 1). When compared with the smart frame, the conventional frame lacks structural stability and construction safety during the erection process; this makes it less advantageous in terms of the time and cost. Considering the site conditions, we established alternatives (see Figure 6) and evaluated factors, such as the crane path, time, and cost, to decide a final erection plan (see Table 3).

Figure 9 shows the actual schedule for PC erection and $\mathrm{RC}$ core works of the case study that has been set according to Figure 5(b). There is not much difference in the erection time among the Zones A1 to A5, B1 to B6, and $\mathrm{C} 1$ to $\mathrm{C} 5$. We can see that there is a significant difference in the time required to erect the PC components left at the crane paths after completing the erection of the zones. In other words, the PC erection time of the A6 to A9 zones differ from that of the $\mathrm{B} 7$ to $\mathrm{B} 10$ and $\mathrm{C} 6$ to $\mathrm{C} 8$ zones, which is approximately more than 3 weeks and 1 month. This is because there are more PC components left at the crane path of Zone A than Zones B and C, as shown in
Figure 5(b). The section designed for the application of the steel frames should be completed before leaving the zone. Zone A6 needs to be erected after completing the steel frame (AS1) work of the upper A6 shown in Figure 5(b); therefore, there is a time interval of approximately two calendar weeks at the $(\mathrm{M}+4)$ th month of Zone $\mathrm{A}$, as shown in Figure 8. In addition, A9 can be erected only after the steel frame (AS2) work of the lower A8 is completed; therefore, there is a delay of 10 calendar days for the PC erection. The erection work was done 5 days per week for 8 hours each day.

Unlike the steel-joint smart frames, the PC frame erection schedule had three problems with respect to the erection time. First, the erection time of the unit PC component for the PC frame was longer than that of the CPC for the smart frame. In Figure 3, the installation of the PC columns and girders involved a series of critical activities, including joint grouting and filling, PC slab installation, and topping with concrete, to secure structural stability and construction safety. Moreover, unlike connected steel CPCs, a simple saddling connection was applied for the PC columns and girders. This connection itself was timeconsuming. For instance, the average erection periods of the unit column, girder, and slab for the PC frame were 39,29 , and $12 \mathrm{~min}$, respectively. However, the average erection periods of the unit column, girder, and slab for the smart frame was 13,10 , and $12 \mathrm{~min}$, respectively. As a result, the average amount of $\mathrm{PC}$ components that a crane could erect in one day was 5 columns, 6 girders, and 8 slabs for the PC frame. However, 12 columns, 12 girders, and 17 slabs could be erected for the smart frame. 

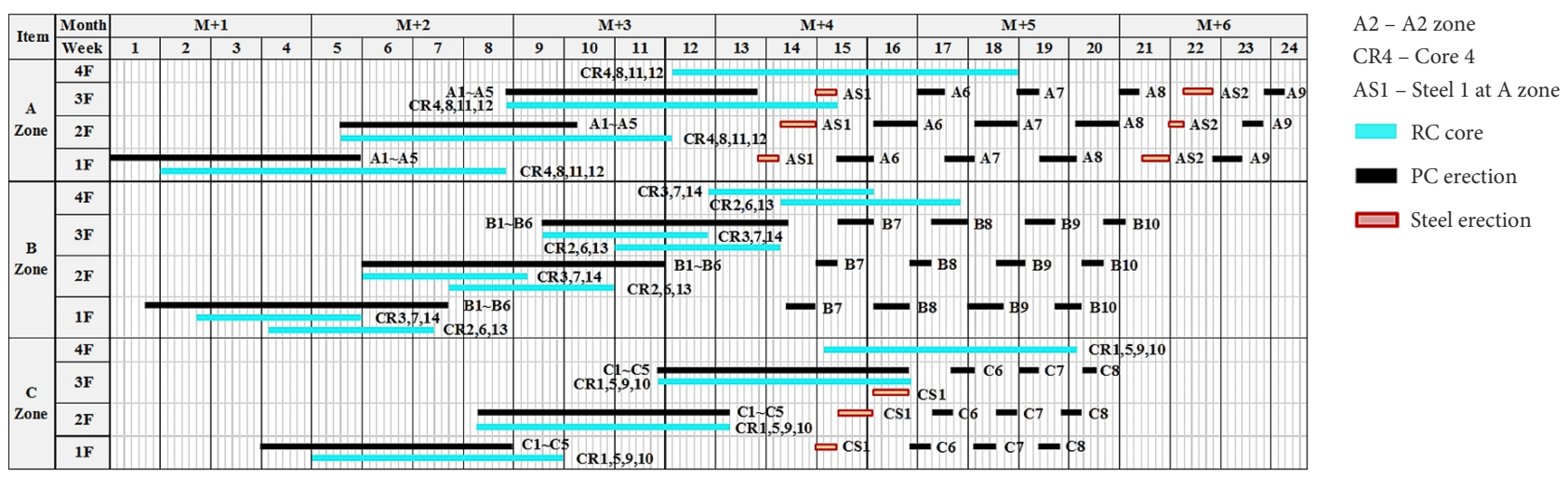

Figure 9. Actual erection schedule of the case project

Second, floor-by-floor erection was our first priority for the PC frame to secure structural stability and construction safety; cascade erection was applied for partial spans. If section-by-section erection was adopted, the crane-moving path would drop more than threefold. For example, in Figure 8, if the first to the third floors of the A1 to A5 zones were to be erected, we would need to move the heavy-capacity crane back and forth in the zones at least three times; this would make the erection was more time-consuming. Also, additional time was required for erection at the $\mathrm{A} 6-\mathrm{A} 9, \mathrm{~B} 7-\mathrm{A} 10$, and $\mathrm{C} 6-\mathrm{A} 8$ zones that were used as crane paths.

Third, the construction of the RC cores (see Figure 9) was the most time-consuming critical activity because the RC core walls of the PC frame were very thick and designed for heavy reinforcement to resist lateral forces. For reference, the floor height of the $\mathrm{RC}$ core was $10 \mathrm{~m}$. Thus, the scaffolding safety needed to be performed inside and outside the core for the rebar and form works, and the concrete needed to be poured twice. Each floor required 17 days. These problems were previously mentioned in Table 1. We can expect the structural performance and erection of the smart frame to be similar to those of steel frames; therefore, the above-mentioned problems will be solved resulting in dramatic time reduction.

\section{Time reduction by using the smart frame}

\subsection{Erection time analysis of the smart frame}

In this study, we compared the reduction in erection time between a smart frame and a frame using PC components. The case building had been initially designed using PC components; we redesigned it using a smart frame consisting of CPC components. The study was conducted in three steps. First, we established the alternatives to the erection plans that reflected the characteristics of the smart frame. Second, the erection time of each alternative was estimated and compared with that of the conventional PC frame. Third, we estimated the cost reduction arising from the time reduction. As shown in Figure 2 and Table 1, smart frames have features and advantages that are similar to those of steel frames. In addition, as shown in Figure 3, the components were erected with simpler activities and quickly fabricated using a tapered connection with an L-shaped steel angle (see Figure 4).

From Figure 6, we can see that five alternatives to the erection plans for the smart frame could be drawn under the same site conditions of the PC frame. Here Plan 2 was excluded because it was difficult to carry out the erection similar to the PC frame. The remaining erection plans are specified in Figure 10. We adopted section-by-section erection for the smart frame to minimize the crane-moving path; therefore, detailed zoning was possible, as shown in Figure 10. When the erection time was calculated based on the erection work that lasted five eight-hour days every week for each plan, Plan 3 had the shortest erection time (78 days); four cranes were used for erection. Three cranes were used for Plan 4 and Plan 5, which required 95 days and 89 days, respectively, for erection.

The smart frame reduced the erection time to half or more than half of erection time required for the PC frame, which needed 172 calendar days for erection (see Table 4). This was because the three problems stated for the PC frame erection schedule had been solved. In particular, as shown in Figure 5(b) and Figure 8, the PC frame applied with floor-by-floor and cascade erection plans use up the crane paths to secure structural stability during erection; this results in a longer erection time. However, a smart frame adopts section-by-section erection, as shown in Figure 10, which reduces the erection time. Figure 11 shows an erection simulation for Plan 5 of the smart frame with the shortest erection time when three cranes were used just like in the case project. Unlike Figure 8, Figure 11 does not have any activity that involves the crane paths.

Plans 1, 3, and 4 also show that the erection time was reduced to approximately $40 \sim 50 \%$ of the floor-by-floor erection time. In the case of the PC structure with a large floor area (see Figures 5 and 8), arranging cranes inside the building was unavoidable, and floor-by-floor erection was adopted for structural stability and construction safety. In such cases, it was confirmed that additional erection time related to the crane paths is required, as shown in Figures 8 and 9; this ultimately extends the construction time. 
a) Plan 1

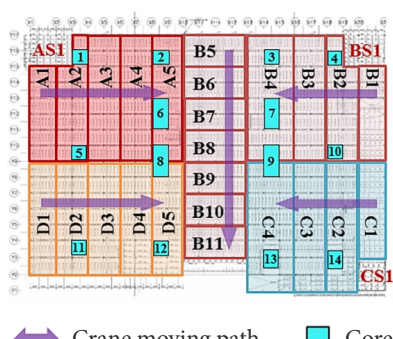

Crane moving path b) Plan 3

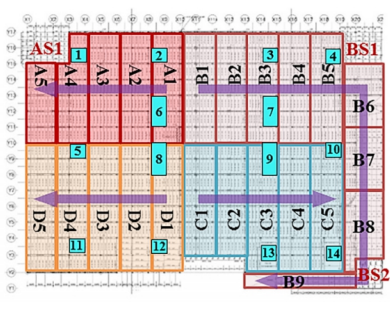

c) Plan 4

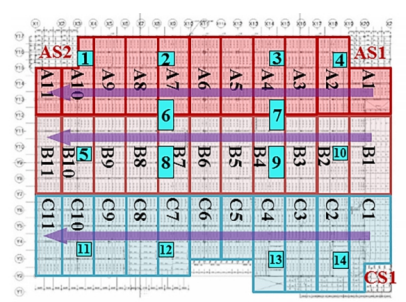

d) Plan 5

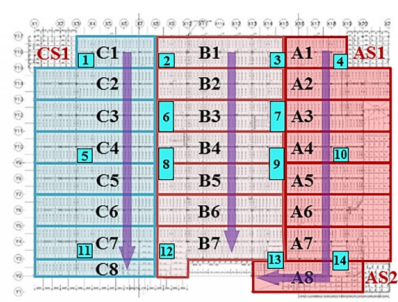

Steel

Figure 10. Erection plans of alternatives

a) $\mathrm{M}+1$

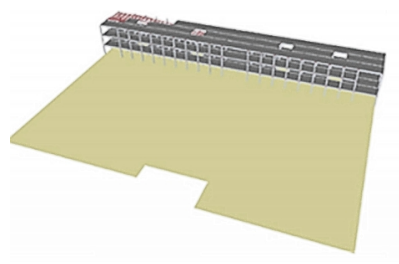

b) $M+2$

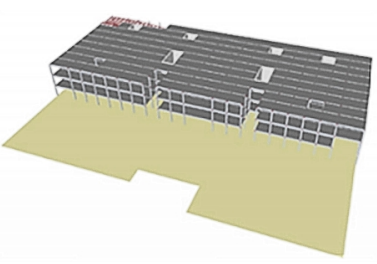

c) $\mathrm{M}+3$

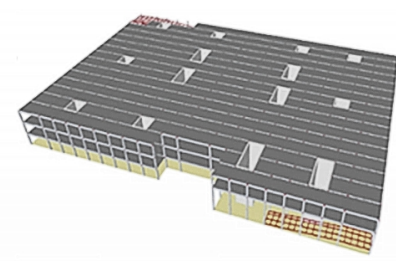

Figure 11. Erection simulation for Plan 5 of the smart frame

Table 4. Erection time analysis of the smart frame (in calendar days)

\begin{tabular}{|l|c|c|c|c|c|}
\hline \multirow{2}{*}{ Alternatives } & \multicolumn{4}{|c|}{ Zone } & \multirow{2}{*}{ Time required } \\
\cline { 2 - 6 } & A & B & C & D & \\
\hline PC frame & 172 & 146 & 123 & - & 172 \\
\hline Plan 1 & 54 & 105 & 54 & 57 & 105 \\
\hline Plan 3 & 60 & 78 & 63 & 68 & 78 \\
\hline Plan 4 & 89 & 92 & 95 & & 95 \\
\hline Plan 5 & 87 & 89 & 86 & & 89 \\
\hline
\end{tabular}

Figure 12 shows the erection schedule of the smart frame (Plan 5). It differs from the actual schedule of the case project illustrated in Figure 9. First, the smart frame was used for the erection plans in which the 1st to 3rd floors of each zone (i.e., Zones A1-A8, B1-B7, and C1-C8) were completed before moving onto the next zone. In the erection plans of the conventional PC frame, the first floors of all the zones are completed before moving onto the next floor. Second, none of the activities shown in Figure 12 used up the crane paths. such as A6-A9, B7-B10, and C6C8 (see Figure 9). Third, the activities of the RC cores were relatively shorter in Figure 12 than in Figure 9. As stated previously, this was because the RC core walls of the PC frame were designed for resisting lateral forces with very thick walls and heavy reinforcement. However, the RC cores in the smart frame were simple vertical pass ways; therefore, they were designed with relatively thin walls and light reinforcement. Furthermore, the erection time of the CPC components was shorter than that of the PC components, which reduced the overall construction time.

\subsection{Erection cost analysis of the smart frame}

The cost reduction caused by the reduced erection time of the smart frame directly decreases the labor and equipment costs. Indirectly, this may reduce the site manage- ment costs owing to the reduced erection time, and it may shorten the payback period of investment because of early completion (Lee et al., 2016; Kim et al., 2010). Additionally, when steel-joint CPC components of the smart frame were used instead of the PC frame, there was no increase in the material costs. In several studies, we found that the material costs decreased by approximately 2-3\% (Joo, Kim, Lee, \& Lim, 2012b; S. H. Lee, S. H. Kim, G. J. Lee, S. K. Kim, \& Joo, 2012). This was because although the steel section may be added when the smart frame is applied instead of the PC frame, the rebar quantity decreases and the section size of the components reduces. This ultimately reduces the amount of concrete required (S. Kim, Hong, Ko, \& J. T. Kim, 2013). It might be too complicated to calculate the cost reduction other than the direct; therefore, the study analyzes only the direct cost reduction that is simple and clear.

Above all, the erection time based on the calendar day stated in Table 4 should be changed to the working day to estimate the labor cost. For example, it takes 54 calendar days to complete Zone A of Plan 1 assuming that people work five days a week. However, the working days excluding holidays and rainy days are only 36 days, as shown in Table 5. Table 5 shows the erection time listed in Table 4, which is converted into working day units. The PC frame needs 311 crews, whereas smart frame requires a minimum of 174 crews, and a maximum of 183 crews. Next, the number of crew members should be checked to estimate human resources for each zone. The erection work of the case project required seven persons per crew, that is, one signal man, two persons for the ground floor, and four persons for the upper floor. For instance, Zone A of Plan 1 requires 36 crews $\times 7$ persons $/$ crew $=252$ man-days (MDYs). The input human resources for each plant of the smart frame and the PC frame was calculated by using the above method, and the results are shown in Table 6 . 

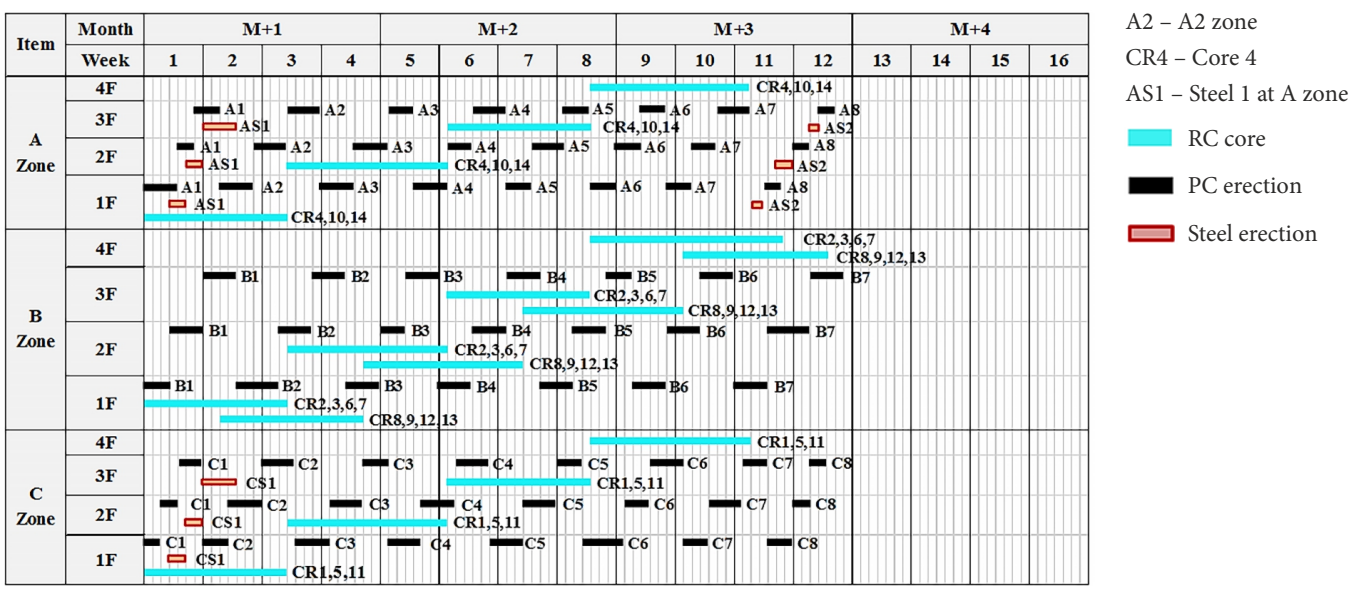

Figure 12. Erection schedule of the smart frame (Plan 5)

Table 5. Working days of each zone and input crews

\begin{tabular}{|l|c|c|c|c|c|}
\hline \multirow{2}{*}{ Type } & \multicolumn{4}{|c|}{ Zone } & \multirow{2}{*}{ Total days } \\
\cline { 2 - 5 } & $\mathrm{A}$ & $\mathrm{B}$ & $\mathrm{C}$ & $\mathrm{D}$ & \\
\hline PC Frame & 121 & 103 & 87 & - & 311 \\
\hline Plan 1 & 36 & 70 & 36 & 38 & 180 \\
\hline Plan 3 & 40 & 52 & 42 & 45 & 179 \\
\hline Plan 4 & 59 & 61 & 63 & - & 183 \\
\hline Plan 5 & 58 & 59 & 57 & - & 174 \\
\hline
\end{tabular}

It takes 2,177 MDYs for the PC frame. For the smart frame, the plane requires a minimum of 1,218 MDYs and a maximum of 1,281 MDYs.

Table 7 shows the actual labor cost paid for the case project (168.14 USD/MDY). For instance, the estimated labor cost for Zone A of Plan 5 was $406 \mathrm{MDY} \times 168.14 \mathrm{USD} /$ $\mathrm{MDY}=68,265$ USD. The labor cost of the PC frame was 366,041 USD. However, the smart frame labor cost was in the range of 204,796 215,388 USD. Thus, the labor cost of the smart frame was $41.2 \sim 44.1 \%$ less than that of the PC frame.

The amount of equipment to be used should be calculated to estimate the equipment cost. Unlike the human resources calculation, which was based on the working day, the equipment quantity of heavy-duty cranes was calculated based on the calendar day. The equipment quantity and cost were decided based on the rental terms and conditions because heavy-duty cranes that exceeded 500 tons could not be transported as a single piece; they

Table 7. Labor cost (Unit: USD)

\begin{tabular}{|l|c|c|c|c|c|c|}
\hline \multirow{2}{*}{ Type } & \multicolumn{4}{|c|}{ Zone } & \multirow{2}{*}{ Sum } & $\begin{array}{c}\text { Reduction } \\
\text { Ratio (\%) }\end{array}$ \\
\cline { 2 - 5 } & A & B & C & D & & - \\
\hline $\begin{array}{l}\text { PC } \\
\text { Frame }\end{array}$ & 142,415 & 121,229 & 102,397 & - & 366,041 & - \\
\hline Plan 1 & 42,371 & 82,389 & 42,371 & 44,725 & 211,856 & 42.1 \\
\hline Plan 3 & 47,079 & 61,203 & 49,433 & 52,964 & 210,679 & 42.4 \\
\hline Plan 4 & 69,442 & 71,796 & 74,150 & - & 215,388 & 41.2 \\
\hline Plan 5 & 68,265 & 69,442 & 67,088 & - & 204,795 & 44.1 \\
\hline
\end{tabular}

Table 6. Input human resources (man-days)

\begin{tabular}{|l|c|c|c|c|c|}
\hline \multirow{2}{*}{ Type } & \multicolumn{4}{|c|}{ Zone } & \multirow{2}{*}{ Total days } \\
\cline { 2 - 5 } & $\mathrm{A}$ & $\mathrm{B}$ & $\mathrm{C}$ & $\mathrm{D}$ & \\
\hline PC Frame & 847 & 721 & 609 & - & 2,177 \\
\hline Plan 1 & 252 & 490 & 252 & 266 & 1,260 \\
\hline Plan 3 & 280 & 364 & 294 & 315 & 1,253 \\
\hline Plan 4 & 413 & 427 & 441 & - & 1,281 \\
\hline Plan 5 & 406 & 413 & 399 & - & 1,218 \\
\hline
\end{tabular}

had to be disassembled before transportation. Then, they needed to be reassembled before use and disassembled thereafter for return. The equipment rental period was basically monthly for the case project, and the minimum rental period was weekly after more than one month. For example, when it took 32 calendar days for the work, the rental period was one month and one week. Table 8 shows the estimated result when the equipment quantity of the case project was calculated under the above conditions. As stated in Table 8, the equipment quantity of the PC frame for each zone was large. Unlike the smart frame that required 8.70 9.15 equipment months (EQMs), the PC frame needed 15.60 EQMs.

The equipment quantity in Table 8 was converted into the equipment cost, as shown in Table 9. For the PC frame, 909,728 USD was paid for the equipment. However, the estimated cost was in the range of 530,970 585,836 USD for each plan when the smart frame was adopted. Therefore, we can conclude that using the smart frame

Table 8. Input equipment (EQMs)

\begin{tabular}{|l|c|c|c|c|c|}
\hline \multirow{2}{*}{ Type } & \multicolumn{4}{|c|}{ Zone } & \multirow{2}{*}{$\begin{array}{c}\text { Total } \\
\text { EQMs }\end{array}$} \\
\cline { 2 - 5 } & $\mathrm{A}$ & $\mathrm{B}$ & $\mathrm{C}$ & $\mathrm{D}$ & \\
\hline PC Frame & 5.63 & 5.04 & 4.94 & - & 15.60 \\
\hline Plan 1 & 1.80 & 3.44 & 1.80 & 1.90 & 8.94 \\
\hline Plan 3 & 2.00 & 2.60 & 2.10 & 2.25 & 8.95 \\
\hline Plan 4 & 2.95 & 3.05 & 3.15 & - & 9.15 \\
\hline Plan 5 & 2.90 & 2.95 & 2.85 & - & 8.70 \\
\hline
\end{tabular}


Table 9. Equipment cost (Unit: USD)

\begin{tabular}{|l|c|c|c|c|c|c|}
\hline \multirow{2}{*}{ Type } & \multicolumn{4}{|c|}{ Zone } & \multirow{2}{*}{ Sum } & \multirow{2}{*}{ Reduction Ratio (\%) } \\
\cline { 2 - 7 } & A & B & C & D & & - \\
\hline PC Frame & 328,316 & 298,228 & 283,184 & - & 909,728 & 36.4 \\
\hline Plan 1 & 123,893 & 207,078 & 123,893 & 123,893 & 578,757 & 35.6 \\
\hline Plan 3 & 123,893 & 169,025 & 138,937 & 153,981 & 585,836 & 38.3 \\
\hline Plan 4 & 176,990 & 192,034 & 192,034 & - & 561,058 & 41.6 \\
\hline Plan 5 & 176,990 & 176,990 & 176,990 & - & 530,970 & \\
\hline
\end{tabular}

instead of the PC frame will reduce $35.6 \sim 41.6 \%$ of the cost. For reference, the monthly and weekly rental fees of the case project were 53,097 USD and 15,044 USD respectively. Also, the cost for mobilizing and demobilizing a crane was 17,699 USD. For instance, the equipment rental cost for Zone A of Plan 5 was 176,990 USD $(53,097 \mathrm{USD} /$ month $\times 3$ months $+15,044 \mathrm{USD} /$ week $\times$ 0 week $+17,699$ USD).

The labor and equipment cost reduction that result from the time reduction are shown in Table 10. It is estimated that the PC frame requires 1,275,769 USD, whereas the smart frame requires $735,765 \sim 796,515$ USD. Therefore, we concluded that all the erection plans of the smart frame may result in a cost reduction of $37.6 \sim 42.3 \%$ when compared with the PC frame.

In particular, the erection time of Plan 3 that applied the smart frame (see Table 4) was only 78 days, which was the shortest; however, its cost reduction was the lowest (see Table 10) because four cranes were used. It took 89 days for the erection when Plan 5 was used (see Table 4) with only three cranes. Thus, the equipment was operated effectively under the rental conditions, which resulted in the lowest equipment cost, as shown in Table 9. As a result, the cost reduction of the smart frame against the PC frame was ultimately quite high. Although increasing the equipment quantity may shorten the erection time, the equipment cost accounts for a large portion of the erection cost, which results in lower cost reduction. In particular, we required an additional 17,699 USD for the mobilization and demobilization for every additional crane unit.

For reference, in terms of overall cost including PC production cost in plant and transportation cost, SMART frame has about $6.6 \%$ cost reduction effect compared to PC frame. The reason is that erection cost accounts for $15.5 \%$ of the overall cost in the case project, while in-plant PC production cost and transportation cost are $76 \%$ and $8.5 \%$ of the overall cost, respectively.

Table 10. Cost reduction (Unit: USD)

\begin{tabular}{|l|c|c|c|c|}
\hline \multicolumn{1}{|c|}{ Type } & $\begin{array}{c}\text { Labor } \\
\text { cost }\end{array}$ & $\begin{array}{c}\text { Equipment } \\
\text { cost }\end{array}$ & Sum & $\begin{array}{c}\text { Reduction } \\
\text { ratio (\%) }\end{array}$ \\
\hline PC Frame & 366,041 & 909,728 & $1,275,769$ & - \\
\hline Plan 1 & 211,856 & 578,757 & 790,613 & 38.0 \\
\hline Plan 3 & 210,679 & 585,836 & 796,515 & 37.6 \\
\hline Plan 4 & 215,388 & 561,058 & 776,446 & 39.1 \\
\hline Plan 5 & 204,795 & 530,970 & 735,765 & 42.3 \\
\hline
\end{tabular}

\section{Discussion}

As shown in Table 4, the erection time of the smart frame was reduced by $40 \sim 50 \%$ as compared with that of the PC frame. In addition, we concluded that the direct cost of the smart frame was approximately 40\%, as shown in Table 10. According to the cost analysis of the case study, heavily loaded long-span logistics buildings use heavy-duty cranes that weigh approximately 500 tons; therefore, the impact of the equipment cost on the overall construction cost was greater than that of the labor costs. Therefore, it is desirable to use the least amount of equipment and simultaneously satisfy the required construction time. However, if the erection time is insufficient, the equipment quantity should be increased even when the partial cost may increase. In other words, time and cost are major factors.

The time-cost conflict was influenced by the erection plan, and the time and cost for each plan needed to be quickly estimated to support decision-making. However, it takes time and effort to estimate the erection time and cost suitable for various plans. In this study, we confirmed that the cost reduction corresponding to the time reduction can be defined by using a mathematical equation. Therefore, we can mathematically define the logical relationship that reflects the zoning of each erection plan, the human resources arrangement, and the equipment rental conditions.

Figure 13 represents the erection plans illustrated in Figure 5(b) and Figure 10 in the matrix form. For instance, the erection times of Zones A, B, C, and D for the erection plan in Figure 10(a) corresponds to $Z_{11}, Z_{21}, Z_{31}$, and $Z_{41}$ of Figure 13(a). Accordingly, the erection of A1-A5, B1-B11, C1-C4, and D1-D5 in Figure 10(a) is applicable to $S_{11}-S_{51}, S_{12}-S_{112}, S_{13}-S_{43}$, and $S_{14}-S_{54}$ of Figure $13(\mathrm{~b})$. The erection cost per plan is given as follows:

$$
\begin{aligned}
& C_{\text {erect plan } k}=\sum_{j=1}^{m} C_{\text {erect zone } j}= \\
& \sum_{j=1}^{m} C_{\text {labor zone } j}+\sum_{j=1}^{m} C_{\text {equipt zone } j}= \\
& \sum_{j=1}^{m} \sum_{i=1}^{l} Q M_{i j} \times U R_{\text {labor }}+\sum_{j=1}^{m}\left(\left(E Q M_{j} \times M R C\right)+\right. \\
& \left.\left(E Q W_{j} \times W R C\right)+C M_{j}\right), \\
& i=1,2, \ldots, l ; j=1,2, \ldots, m,
\end{aligned}
$$


here:

$$
\begin{aligned}
& \sum_{i=1}^{l} Q M_{i j}=\sum_{i=1}^{l} S_{i j} \times N_{\text {crew }} ; \\
& E Q M_{j}=\text { Rounddown }\left(\frac{\text { Ceiling }\left(E Q D_{j}, \frac{30}{4}\right)}{30}, 0\right) ; \\
& E Q W_{j}=\text { Roundup }\left(\frac{\text { Ceiling }\left(E Q D_{j}, \frac{30}{4}\right)-\left(E Q M_{j} \times 30\right)}{7.5}, 0\right) ; \\
& E Q D_{j}=\sum_{i=1}^{l} S_{i j} \times \frac{30}{20},
\end{aligned}
$$

where: $Q M_{i j}$ - human resources in working days (MDY); $U R_{\text {labor }}$ - unit rate of human resources (USD/MDY); $S_{i j}$-erection time of section $i$ in Zone $j$ in a working day (day); $N_{\text {crew }}$ - number of workers per crew (worker/crew); $E Q M$ - equipment quantity in calendar month; $E Q W$ equipment quantity in calendar week; $M R C$ - monthly rental cost of equipment (USD/month); WRC - weekly rental cost of equipment (USD/week); $E Q D_{j}$ - equipment quantity of Zone $j$ in a calendar day; $C M_{j}$ - Equipment mobilization and demobilization cost for Zone $j$ (USD).

Using Eqn (1), we calculated the erection cost by adding up the cost of each zone, and this cost was again estimated in the division of labor and equipment cost. The labor cost was calculated by multiplying the human resources in a working day by the unit rate of human resources, and the equipment cost was estimated using the equipment quantity and the rental fee in a calendar month and week, which included the mobilization and demobilization cost. Eqn (2) is applied to calculate the human resources in a working day, and the sum of Zone $j$ in Figure 13(b).

a) Zoning matrix of erection plans

\begin{tabular}{|c|c|c|c|c|c|}
\hline Description & Plan 1 & Plan 2 & Plan 3 & Plan 1 & Plan $k$ \\
\hline Zone 1 & $Z_{11}$ & $Z_{12}$ & $Z_{13}$ & $\cdots$ & $Z_{1 k}$ \\
\hline Zone 2 & $Z_{21}$ & $Z_{22}$ & $Z_{23}$ & $\cdots$ & $Z_{2 k}$ \\
\hline Zone 3 & $Z_{31}$ & $Z_{32}$ & $Z_{33}$ & $\cdots$ & $Z_{3 k}$ \\
\hline$\vdots$ & $\vdots$ & $\vdots$ & $\vdots$ & $\ddots$ & $\vdots$ \\
\hline Zone $j$ & $Z_{j 1}$ & $Z_{j 2}$ & $Z_{j 3}$ & $\cdots$ & $Z_{j k}$ \\
\hline
\end{tabular}

b) Decomposition of zones in a erection plan

\begin{tabular}{|c|c|c|c|c|c|}
\hline Description & Zone 1 & Zone 2 & Zone 3 & Zone 1 & Zone $j$ \\
\hline Section 1 & $S_{11}$ & $S_{12}$ & $S_{13}$ & $\cdots$ & $S_{1 j}$ \\
\hline Section 2 & $S_{21}$ & $S_{22}$ & $S_{23}$ & $\cdots$ & $S_{2 j}$ \\
\hline Section 3 & $S_{31}$ & $S_{32}$ & $S_{33}$ & $\cdots$ & $S_{3 j}$ \\
\hline$\vdots$ & $\vdots$ & $\vdots$ & $\vdots$ & $\ddots$ & $\vdots$ \\
\hline Section $i$ & $S_{i 1}$ & $S_{i 2}$ & $S_{i 3}$ & $\cdots$ & $S_{i j}$ \\
\hline
\end{tabular}

Figure 13. Matrix interpretation of the erection plans
Eqn (3) is the equipment quantity in a calendar month, and Eqn (4) is the equipment quantity in a calendar week in Zone $j$ according to the equipment rental conditions. Eqn (5) is the conversion of the erection time in a working day into the erection time in a calendar day in which the calendar day per month is 30 days and the working day is 20 days. This is done because the equipment is rented based on the calendar day. For reference, the above equations are defined based on zones because one unit of crane is arranged for each zone.

In order to verify the proposed mathematical formulas, we apply them to the case of Plan 5 as follows.

When erection time of Plan 5 in a working day is calculated according to Figure 13(b), the result it is shown in Table 11. As shown in Table 11, the erection time and Eqn (2) calculate the manpower by Eqn (6). When manpower is estimated by the erection time of Table 11 and Eqn (2), the result is the same as Eqn (6).

$$
\begin{aligned}
& \sum_{j=1}^{m} \sum_{i=1}^{l} Q M_{i j}=\sum_{j=1}^{m} \sum_{i=1}^{l} S_{i j} \times N_{c r e w}= \\
& (58+59+57) \times 7=1,218 \mathrm{MDYs}, \\
& i=1,2, \ldots, l ; j=1,2, \ldots, m .
\end{aligned}
$$

In order to get the equipment cost, when calculating the equipment quantity of each zone in a calendar day by using Eqn (5), the results are the same as Eqns (7), (8) and (9).

$$
\begin{aligned}
& E Q D_{1}=\left(58 \times \frac{30}{20}\right)=87 \text { days; } \\
& E Q D_{2}=\left(59 \times \frac{30}{20}\right)=89 \text { days; } \\
& E Q D_{3}=\left(57 \times \frac{30}{20}\right)=86 \text { days. }
\end{aligned}
$$

According to the equipment rental condition, when converting the results of Eqns (7), (8) and (9) to the monthly and weekly equipment quantities, the results are the same as Eqns (10) and (11).

$$
\sum_{j=1}^{3} E Q M_{j}=\text { Rounddown }\left(\frac{\text { Ceiling }\left(E Q D_{j}, \frac{30}{4}\right)}{30}, 0\right)=
$$

Table 11. Erection time of Plan 5 in a working day (days)

\begin{tabular}{|l|c|c|c|}
\hline \multicolumn{1}{|c|}{ Description } & Zone 1 & Zone 2 & Zone 3 \\
\hline Section 1 & 6 & 9 & 5 \\
\hline Section 2 & 8 & 9 & 8 \\
\hline Section 3 & 7 & 7 & 8 \\
\hline Section 4 & 7 & 8 & 8 \\
\hline Section 5 & 8 & 8 & 8 \\
\hline Section 6 & 8 & 9 & 8 \\
\hline Section 7 & 8 & 9 & 8 \\
\hline Section 8 & 6 & - & 4 \\
\hline Sum & 58 & 59 & 57 \\
\hline
\end{tabular}




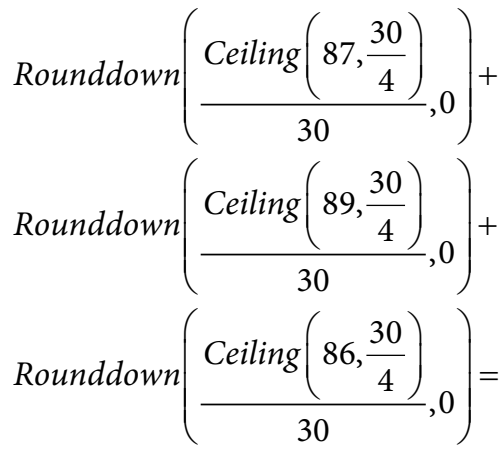

$3+3+3=9$ months;

$$
\begin{aligned}
& \sum_{j=1}^{3} E Q W_{j}=\text { Roundup }\left(\frac{\text { Ceiling }\left(E Q D_{j}, \frac{30}{4}\right)-\left(E Q M_{j} \times 30\right)}{7.5}, 0\right)= \\
& 0+0+0=0 \text { week. }
\end{aligned}
$$

For reference, equipment rental conditions are divided monthly and weekly. And weekly rental cost is slightly higher than $1 / 4$ of monthly rental cost. It is therefore advantageous to rent monthly if the equipment is used for more than three weeks. Rounddown, Roundup and Ceiling functions are used to calculate monthly and weekly equipment quantities to reflect these conditions. In other words, applying the Ceiling $\left(E Q D_{j}, 30 / 4\right)$ in Eqns (10) and (11) means renting monthly if the equipment is used for more than three weeks. Plan 5 requires equipment for 87, 89 and 86 calendar days, such as Eqns (7), (8) and (9). In this case, it is advantageous to rent a total of 9 months for 3 months each, which means that it is advantageous not to do the weekly rent.

Finally, the result of calculating the total erection cost using Eqn (1) is the same as Eqn (12). For reference, as described in Section 3.2, the labor unit rate is 168.14 USD/ day and the equipment rental cost is 53,097 USD/month and 15,044 USD/week. And the cost for mobilizing and demobilizing a crane is 17,699 USD.

$$
\begin{aligned}
& C_{\text {erect plank }}=\sum_{j=1}^{m} C_{\text {erect zone } j}= \\
& \sum_{j=1}^{m} C_{\text {labor zone } j}+\sum_{j=1}^{m} C_{\text {equipt zone } j}= \\
& \sum_{j=1}^{m} \sum_{i=1}^{l} Q M_{i j} \times U R_{\text {labor }}+\sum_{j=1}^{m}\left(\left(E Q M_{j} \times M R C\right)+\right. \\
& \left.\left(E Q W_{j} \times W R C\right)+C M_{j}\right)= \\
& (1,218 \mathrm{MDY} \times 168.14 \mathrm{USD} / \mathrm{MDY})+ \\
& (9 \text { months } \times 53,097 \mathrm{USD} / \mathrm{month})+ \\
& (0 \text { week } \times 15,044 \mathrm{USD} / \mathrm{month})+ \\
& (3 \text { cranes } \times 17,699 \mathrm{USD} / \mathrm{crane})= \\
& 735,765 \mathrm{USD}, j=1,2, \ldots, m .
\end{aligned}
$$

The maximum erection time of Plan 5 estimated by the proposed formula is 89 days and the erection cost is 735,765 USD. Since these results are the same as the ones in Table 4 and Table 10, the proposed formula is verified.
A variety of erection plans can be set for large PC buildings similar to the case project mentioned in the study, and each plan may have the time and cost conflicts as stated earlier. Therefore, it is very important to quickly check for the conflicts to decide the erection plan. In addition to confirm the time reduction provided by the smart frames, we obtained results to develop mathematical equations that accurately and quickly calculated the time and cost for the erection planning alternatives. The proposed equations may be used to effectively and quickly decide a final erection plan.

\section{Conclusions}

A smart frame is an erection technology developed to improve upon the disadvantages associated with the conventional PC frame. In this study, we analyzed the direct cost reductions resulting from a shortened erection time when a heavily loaded long-span logistics building designed using a conventional PC frame was replaced by a steel-joint smart frame. A case project was chosen for this analysis. Data on the actual time and cost input was compared with the simulation data of the smart frame that was proposed as an alternative. We confirmed the following in the study. Heavily loaded long-span logistics buildings with large floor areas were divided into zones and sections and arranged using several cranes for completion within a target date. Also, floor-by-floor erections were adopted for the pin-joint PC frame just like the case project to secure structural stability and construction safety. In this case, the crane path was used up, which increased the erection time. However, we performed a section-by-section erection of the steel-joint smart frame, and this significantly reduced the erection time. Furthermore, besides the matters specified in Table 1, the CPC components of the smart frame can be erected more quickly and safely with a tapered connection than with the PC components of a PC frame.

The following results were drawn from the study. First, we confirmed that the erection time of the smart frame was reduced by approximately $50 \%$ as compared with the erection time of the PC frame.

Second, we found that the direct cost decreased by $37.6 \sim 42.3 \%$ as compared with that of the PC frame because of the time reduction. To be more specific, the labor cost decreased by $41.2 \%$ to $44.1 \%$, and the equipment cost decreased by $35.6 \%$ to $41.6 \%$. Here, we excluded the indirect cost reduction owing to the reduced site management costs influenced by the time reduction and the payback period reduction of the investment because of early completion. If indirect cost reduction was included for analysis in the study, the cost reduction corresponding to the time reduction of the smart frame would be high.

Finally, we confirmed that large PC buildings have a wide range of erection alternatives, which may create a time-cost conflict. Therefore, the time and cost of the alternatives should be precisely and quickly calculated to support rational decision-making that satisfies the project conditions. In this study, we obtained additional results 
for developing the mathematical equations required to accurately and quickly analyze the time and cost conflicts.

The results of this study will contribute to providing time and cost reduction for smart frames used in heavily loaded long-span buildings designed with PC components. Academically, our results will help develop the erection simulation algorithms for smart frames. Furthermore, they will be useful for developing a simulation model to precisely and quickly estimate the conflict of time and cost in the erection plans of large PC buildings.

\section{Acknowledgements}

This work was supported by the National Research Foundation of Korea (NRF) grant funded by the Korea government (MOE) (No. 2017R1D1A1B04033761).

This work was supported by the National Research Foundation of Korea (NRF) grant funded by the Korea government (Ministry of Science and ICT) (NRF-2018M2B2B1065635).

\section{Funding}

This work was supported by the National Research Foundation of Korea (NRF) grant funded by the Korea government (MOE) (No. 2017R1D1A1B04033761).

This work was supported by the National Research Foundation of Korea (NRF) grant funded by the Korea government (Ministry of Science and ICT) (NRF-2018M2B2B1065635).

\section{Author contributions}

H. H. Lee was responsible for analyzing the time and cost reduction effects of SMART frame and drafted the paper. K. H. Kim and S. Son were responsible for analyzing the erection time of the case project and simulating the erection plans of SMART frame. K. Park supported the time and cost reduction effects of SMART frame. S. Kim participated in the development of the SMART frame, consulted on the construction of the case project with PC frame, and instructed the overall contents of the paper to be written consistently and logically.

\section{Disclosure statement}

The authors declare that they have no relevant or material financial interests that relate to the research described in this paper.

\section{References}

Arditi, D., Ergin, U., \& Günhan, S. (2000). Factors affecting the use of precast concrete systems. Journal of Architectural Engineering, 6(3), 79-86. https://doi.org/10.1061/(ASCE)1076-0431(2000)6:3(79)

Casadei, P., Nanni, A., Alkhrdaji, T., \& Thomas, J. (2005). Performance of double-T prestressed concrete beams strengthened with steel reinforcement polymer. Advances in Structural Engineering, 8(4), 427-442.

https://doi.org/10.1260/136943305774353124
Choi, H. K., Choi, Y. C., \& Choi, C. S. (2013). Development and testing of precast concrete beam-to-column connections. Engineering Structures, 56, 1820-1835.

https://doi.org/10.1016/j.engstruct.2013.07.021

Elliott, K. S., \& Jolly, C. (2013). Multi-storey precast concrete framed structures. Wiley. Retrieved from https://onlinelibrary. wiley.com/doi/book/10.1002/9781118587379

Fathi, M., Parvizi, M., Karimi, J., \& Afreidoun, M. H. (2018). Experimental and numerical study of a proposed moment-resisting connection for precast concrete frames. Scientia Iranica, 25(4), 1977-1986. https://doi.org/10.24200/SCI.2017.4200

Holden, T., Restrepo, J., \& Mander, J. B. (2003). Seismic performance of precast reinforced and prestressed concrete walls. Journal of Structural Engineering, 129(3), 286-296. https://doi.org/10.1061/(ASCE)0733-9445(2003)129:3(286)

Hong, W. K., Kim, G., Lim, C., \& Kim, S. (2017). Development of a steel-guide connection method for composite precast concrete components. Journal of Civil Engineering and Management, 23(1), 59-66.

https://doi.org/10.3846/13923730.2014.975740

Hong, W. K., Kim, J. M., Park, S. C., Kim, S. I., Lee, S. G., Lee, H. C., \& Yoon, K. J. (2009). Composite beam composed of steel and pre-cast concrete (modularized hybrid system) Part II: analytical investigation. The Structural Design of Tall and Special Buildings, 18(8), 891-905. https://doi.org/10.1002/tal.484

Hong, W. K., Kim, S. I., Park, S. C., Kim, J. M., Lee, S. G., Yoon, K. J., \& Kim, S. K. (2010a). Composite beam composed of steel and precast concrete (modularized hybrid system). Part IV: Application for multi-residential housing. The Structural Design of Tall and Special Buildings, 19(7), 707-727.

https://doi.org/10.1002/tal.506

Hong, W. K., Park, S. C., Lee, H. C., Kim, J. M., Kim, S. I., Lee, S. G., \& Yoon, K. J. (2010b). Composite beam composed of steel and precast concrete (modularized hybrid system). Part III: Application for a 19-storey building. The Structural Design of Tall and Special Buildings, 19(6), 679-706.

https://doi.org/10.1002/tal.507

Hong, W. K., Lee, G., Lee, S., \& Kim, S. (2014). Algorithms for in-situ production layout of composite precast concrete members. Automation in Construction, 41, 50-59. https://doi.org/10.1016/j.autcon.2014.02.005

Hong, W. K., Park, S. C., Kim, S., \& Nzabonimpa, J. D. (2016). Analytical investigation of pre-stressed, pre-cast beams with steel pipe sleeves. The Structural Design of Tall and Special Buildings, 25(1), 60-71. https://doi.org/10.1002/tal.1228

Hong, W. K., Park, S. G., Kim, J. M., Kim, S. I., Yoon, K. J., \& Lee, H. C. (2008). Composite beam composed of steel and precast concrete (Modularized Hybrid System, MHS). Part I: experimental investigation. The Structural Design of Tall and Special Buildings, 19(3), 275-289. https://doi.org/10.1002/tal.485

Hurst, M. K. (2017). Prestressed concrete design. London and New York: Spon Press.

Joo, J. K., Kim, S. E., Lee, G. J., Kim, S. K., \& Lee, S. H. (2012a). A study on the lifting progress for composite precast concrete members of green frame. Korean Journal of Construction Engineering and Management, 13(3), 34-42. https://doi.org/10.6106/KJCEM.2012.13.3.034

Joo, J. K., Kim, S. K., Lee, G. J., \& Lim, C. Y. (2012b). Cost analysis of the structural work of green frame. Journal of the Korea Institute of Building Construction, 12(4), 401-414. https://doi.org/10.5345/JKIBC.2012.12.4.401

Kim, J., Hong, W. K., \& Lim, G. T. (2017). Losses of prestressed forces of pre-tensioned precast composite beams. The Structural Design of Tall and Special Buildings, 26(5), e1339. https://doi.org/10.1002/tal.1339 
Kim, K. H., Lee, T. O., Lee, S. H., \& Kim, S. K. (2012). Comparative analysis of column connection characteristics of green frame. Journal of the Korea Institute of Building Construction, 12(4), 415-425. https://doi.org/10.5345/JKIBC.2012.12.4.415

Kim, S. H., Choi, E. G., Kim, S. K., \& Lee, S. H. (2010). A case study of the improvement of the structural work of a logistics facility by using PC member. Journal of the Korea Institute of Building Construction, 10(6), 127-135. https://doi.org/10.5345/JKIC.2010.12.6.127

Kim, S., Hong, W. K., Kim, J. H., \& Kim, J. T. (2013a). The development of modularized construction of enhanced precast composite structural systems (Smart Green frame) and its embedded energy efficiency. Energy and Buildings, 66, 16-21. https://doi.org/10.1016/j.enbuild.2013.07.023

Kim, S., Hong, W. K., Ko, H. J., \& Kim, J. T. (2013b). The energy efficient expansion remodeling construction method of bearing wall apartment buildings with pre-cast composite structural systems. Energy and Buildings, 66, 714-723. https://doi.org/10.1016/j.enbuild.2013.07.080

Lee, D., Lim, C., \& Kim, S. (2016). $\mathrm{CO}_{2}$ emission reduction effects of an innovative composite precast concrete structure applied to heavy loaded and long span buildings. Energy and Buildings, 126, 36-43. https://doi.org/10.1016/j.enbuild.2016.05.022

Lee, S. H., Kim, S. E., Kim, G. H., Joo, J. K., \& Kim, S. K. (2011). Analysis of structural work scheduling of green frame-focusing on apartment buildings. Journal of the Korea Institute of Building Construction, 11(3), 301-309. https://doi.org/10.5345/JKIC.2011.06.3.301

Lee, S. H., Kim, S. H., Lee, G. J., Kim, S. K., \& Joo, J. K. (2012). Automatic algorithms of rebar quantity take-off of Green Frame by Composite precast concrete members. Korean Journal of Construction Engineering and Management, 13(1), 118128. https://doi.org/10.6106/KJCEM.2012.13.1.118

Lee, S. H., Park, J. Y., Lim, C. Y., \& Kim, S. K. (2013). Constructability analysis of green columns at the low bending moment zone. Journal of Construction Engineering and Project Management, 3(4), 12-19.

https://doi.org/10.6106/JCEPM.2013.3.4.012
Lee, S., Hong, W. K., Lim, C., \& Kim, S. (2015). A dynamic erection simulation model of column-beam structures using composite precast concrete components. Journal of Intelligent \& Robotic Systems, 79(3-4), 537-547.

https://doi.org/10.1007/s10846-014-0115-9

Lim, C. Y., Joo, J. K., Lee, G. J., \& Kim, S. K. (2011). In-situ production analysis of composite precast concrete members of green frame. Journal of the Korea Institute of Building Construction, 11(5), 501-514. https://doi.org/10.5345/JKIBC.2011.11.5.501

Lim, C., Lee, S., \& Kim, S. (2015). Embodied energy and CO2 emission reduction of a column-beam structure with enhanced composite precast concrete members. Journal of Asian Architecture and Building Engineering, 14(3), 593-600. https://doi.org/10.3130/jaabe.14.593

Nawy, E. G. (2008). Concrete construction engineering handbook. CRC Press. https://doi.org/10.1201/9781420007657

Polat, G. (2008). Factors affecting the use of precast concrete systems in the United States. Journal of Construction Engineering and Management, 134(3), 169-178.

https://doi.org/10.1061/(ASCE)0733-9364(2008)134:3(169)

Rajagopal. (2010). Bridging sales and service quality functions in retailing high-technology consumer products. International Journal of Services and Operations Management, 7(2), 177199. https://doi.org/10.1504/IJSOM.2010.034436

Son, S., Lim, J. Y., \& Kim, S. K. (2018). Erection simulation of steel connected precast concrete components for long span and heavy loaded logistics buildings. In 3rd World Congress on Civil, Structural, and Environmental Engineering (CSEE'18), Budapest, Hungary. https://doi.org/10.11159/icsenm18.118

Yardim, Y., Waleed, A. M. T., Jaafar, M. S., \& Laseima, S. (2013). AAC-concrete light weight precast composite floor slab. Construction and Building Materials, 40, 405-410. https://doi.org/10.1016/j.conbuildmat.2012.10.011 